\title{
Longitudinal Multisite Randomized Controlled Trial on the Provision of the EMDR-IGTP-OTS to Refugee Minors in Valencia, Spain
}

\author{
Rosa Josefa Molero', Ignacio Jarero, ${ }^{2,}$, Martha Givaudan ${ }^{2}$ \\ ${ }^{1}$ General Board for the Protection of Childhood and Adolescence, Valencia, Spain \\ ${ }^{2}$ Department of Research, Mexican Association for Mental Health Support in Crisis, Mexico City, Mexico
}

Email address:

rosa.molero@uv.es (R. J. Molero), nacho@amamecrisis.com.mx (I. Jarero), martha@imifap.org.mx (M. Givaudan)

${ }^{*}$ Corresponding author

\section{To cite this article:}

Rosa Josefa Molero, Ignacio Jarero, Martha Givaudan. Longitudinal Multisite Randomized Controlled Trial on the Provision of the EMDRIGTP-OTS to Refugee Minors in Valencia, Spain. American Journal of Applied Psychology. Vol. 8, No. 4, 2019, pp. 77-88. doi: 10.11648/j.ajap.20190804.12

Received: August 13, 2019; Accepted: August 24, 2019; Published: September 11, 2019

\begin{abstract}
The aim of this longitudinal multisite randomized controlled trial (RCT) was to evaluate the effectiveness of the EMDR-Integrative Group Treatment Protocol for Ongoing Traumatic Stress (EMDR-IGTP-OTS) in reducing severe posttraumatic stress disorder, depression, and anxiety symptoms in refugee minors living in Valencia, Spain. The study was conducted in 2019 in the city of Valencia, Spain, in six sites for refugees (homes or residences). A total of 184 minors (all males) met the inclusion criteria. Participants' ages ranged from 13 to 17 years old $(\mathrm{M}=16.36$ years). Participants' time since the arrival to the sites in Valencia varied from January 2018 to March 2019. Participation was voluntary with the participants and their legal guardian's consent. In this study, intensive EMDR therapy was provided. This intensive format allowed the participants to complete the full course of treatment in a short period. Treatment was provided simultaneously by eighteen licensed EMDR clinicians formally trained in the protocol administration divided into six teams. Each of the treatment group participants received an average of eight hours of treatment, provided during nine group-treatment sessions, three times daily during three consecutive days in a setting inside the six refugee sites. EMDR-IGTP-OTS treatment focused only on the distressing memories related to their life as refugees and did not address any other memories. No adverse effects were reported during treatment or at three-month post-treatment assessment. Data analysis by repeated measures ANOVA showed that the EMDR-IGTP-OTS was effective in reducing PTSD symptoms in the treatment group $\left(\mathrm{F}(2,122)=43.17 \mathrm{p}<.001, \eta_{P}{ }^{2}=.414\right)$. A significant effect for group $(\mathrm{F}(1,61=$ 5.52, $\left.\mathrm{p}<.05, \eta_{P}{ }^{2}=.898\right)$ and a significant interaction between time and group for this variable, $(\mathrm{F}(2,122)=11.10, \mathrm{p}<.001$, $\left.\eta_{P}{ }^{2}=.154\right)$ confirmed the effects of the treatment. Significant effects for time $\left(\mathrm{F}(1,61)=7.46, \mathrm{p}<.001, \eta_{P}{ }^{2}=.109\right)$ and for interaction between time and group $\left(\mathrm{F}(1,61)=6.13, \mathrm{p}<.01, \eta_{P}{ }^{2}=.091\right)$ were found for both, anxiety and depression, $(\mathrm{F}(1,61)=$ $\left.7.02, \mathrm{p}<.01, \eta_{P}{ }^{2}=.104\right)$ and $\left(\mathrm{F}(1,61)=7.92, \mathrm{p}<.001, \eta_{P}{ }^{2}=.116\right)$. The study results indicate that the intensive administration of the EMDR-IGTP-OTS could be a feasible, cost-effective, time-efficient, culturally sensitive, and effective component of a multidisciplinary psycho-social group-based program to address PTSD, depression, and anxiety symptoms among refugee minors.
\end{abstract}

Keywords: Eye Movement Desensitization and Reprocessing (EMDR), EMDR-IGTP-OTS,

Posttraumatic Stress Disorder (PTSD), Anxiety, Depression, Minors, Refugees

\section{Introduction}

A refugee is an individual who has crossed an international border based on a well-founded fear of persecution to seek protection in another country, and whose asylum claim has been recognized by the relevant entities [1]. Worldwide, the forcibly displaced population increased in 2017 by 2.9 million. A total of 68.5 million individuals were forcibly displaced worldwide as a result of persecution, conflict, or generalized violence. An estimated 16.2 million people were newly displaced in 2017. This included 11.8 million individuals displaced within the borders of their own 
countries and 4.4 million newly displaced refugees and new asylum-seekers. Developing regions hosted 85 percent (about 16.9 million people) of the world's refugees under the United Nations High Commissioner for Refugees (UNHCR's) mandate. The least developed countries provided asylum to a growing proportion, amounting to one-third of the global total (6.7 million refugees). In 2017, the number of new displacements was equivalent to an average of 44,400 people being forced to flee their homes every day and about 3.1 million people were awaiting a decision on their application for asylum, about half in developing regions. It includes 173,800 unaccompanied and separated children. Children below 18 years of age constituted about half of the refugee population in 2017. By the end of that year, Spain had received 17,561 refugees and people in a refugees-like situation with a total of 54,028 population of concern. [2].

Since 2016, as a consequence of the migratory phenomenon that affects all Spain, the arrival of refugees increased in Valencia, reaching 952 children in 2018, mostly from North Africa (sub-Saharan origin). All of them share the same goal: find a home, definitive or temporary, from where to develop their dreams and their potential supported by adults who care for them. Currently, 4,232 children and adolescents (99\% males) are within Valencia's protection system living in 116 homes (homes are for one to seven minors) or residences (residences are for eight or more minors). Of those, 2,624 are living in homes with families and 1,608 are living in refugee residences. There is no information on the cause that motivates the absence of the arrival of girls in Spanish territory. The organizations say that although girls do leave their countries of origin, they do not arrive in Europe because of their immersion in mafias that are dedicated to child sexual exploitation [3].

The refugee's traumatization is often experienced sequentially (i.e., before, during, and after the flight) [4]. A great percentage of refugees have faced traumatic experiences before arriving in a host country (e.g., killing of family members, violence, war, injury, conflict, torture, persecution, starvation, disease) [5]. During their journey, most of them have experienced a risk of sexual exploitation and trafficking [6]. After arrival in the host country, refugees encounter traumatic stressors (i.e., poverty, lack of social support, discrimination, the feeling of loss, and anxiety for their uncertain future) [7-9]. Up to $91 \%$ of refugee groups in host countries live with posttraumatic stress disorder (PTSD) [10-11]. Rates of $25-30 \%$ for PTSD and $30-43 \%$ for depression have been reported among populations exposed to mass conflict and displacement [12-13]. Since 2004, the UNHCR recommended that mental health services for refugees should be increased and strengthened [14]. PTSD is a mental disorder occurring after exposure to life-threatening episodes (criterion A) and is characterized by intense reliving of the traumatic event through intrusive memories and nightmares (criterion B); avoidance of reminders of the event (criterion $\mathrm{C}$ ); negative alterations in cognition and mood (criterion D); hypervigilance toward potential threats in the environment (criterion E); and in some cases, persistent or recurrent depersonalization symptoms [15].

\subsection{EMDR Therapy}

Eye Movement Desensitization and Reprocessing (EMDR) therapy is a structured, eight-phase comprehensive approach that addresses the past, present, and future aspects of distressing memories of adverse life experiences. It is guided by the Adaptive Information Processing (AIP) model [16]. Briefly stated, the AIP is a model of pathogenesis and change. This unique theoretical model posits that psychopathology is primarily caused by memories of adverse life experiences that have been inadequately processed and maladaptively stored in a state-specific form. The AIP is the cornerstone of EMDR therapy because it interprets clinical phenomena, predicts successful treatment outcomes, and guides clinical practice. EMDR therapy and trauma-focused Cognitive Behavioral Therapy (TF-CBT) are the only psychotherapies recommended for children, adolescents, and adults with PTSD in the WHO Guidelines for the Management of Conditions Specifically Related to Stress [17].

\subsection{EMDR-Integrative Group Treatment Protocol Adapted for Ongoing Traumatic Stress}

The EMDR-integrative group treatment protocol (EMDRIGTP) for early intervention was developed by members of the Mexican Association for Mental Health Support in Crisis (AMAMECRISIS) to deal with the extensive need for mental health services after Hurricane Pauline ravaged the coasts of the states of Oaxaca and Guerrero in the year 1997 [18]. The protocol combines the eight EMDR treatment phases with a group therapy model and an art therapy format and uses the Butterfly Hug (BH) as a form of a self-administered bilateral stimulation [19].

The justification for modifying the standard individual EMDR protocol was to provide mental health services in disaster aftermath circumstances and fulfill the population's mental health needs. The protocol was originally designed for working with children and was later modified for use with adults [20-21]. The protocol compares favorably with group treatment of other models in terms of time, resources, and results [22]. In the EMDR-IGTP, the group setting allows for a group administration of individual treatment, ensuring that many individuals can be treated simultaneously. This is highly valuable in settings where resources are limited. EMDR-IGTP therapy is very different from traditional group therapy (e.g., Yalom, 1970) which fosters interaction between group members, who provide each other with mutual support and validation, and in which group process is considered a primary mechanism of change [23]. It is also very different from Group Trauma-Focused CBT (GTF-CBT) in that TFCBT practice components include developing a trauma narrative and engaging in vivo gradual exposure [24]. Another important difference is confidentiality. While in the EMDR-IGTP treatment, there is strict confidentiality, in GTF-CBT "strict confidentiality by others in the group 
cannot be guaranteed" (p. 62). Studies have used a range of terms to describe EMDR-IGTP such as the EMDR group protocol, the children's EMDR group protocol, and the butterfly hug protocol.

This protocol has been used in its original format or with adaptations to suit the cultural circumstances, in numerous places around the world for thousands of survivors of natural or man-made disasters [25-28]. These include anecdotal reports (29-30); nine pilot field studies with both children and adults after natural mass disasters in Mexico, Nicaragua, El Salvador, Colombia and Venezuela [31-33]; case reports and field studies have documented its effectiveness with children and adults after natural or man-made disasters [3443]; during ongoing war trauma [44]; during ongoing geopolitical crisis [45]; with women sexually assaulted in the Congo [46]; with war refugee children in Germany [47]; with children and adolescents who were victims of severe interpersonal violence [48-50]; with non-governmental organization (NGO's) staff members who provide care to children and adolescents with severe interpersonal trauma [51]; with caregivers of patients with dementia [52]; with Spanish-speaking Latina survivors of domestic violence [53]; with refugee minors in the UK, Turkey, Ethiopia [54-56]; and as an emergency treatment to children survivors of the November 13, 2015 terrorist attacks in Paris [57].

To Stevens et al., existing conceptualizations of traumatic stress, such as PTSD and complex PTSD, may have limited utility for ongoing threat and danger due to the notion that trauma exposure is temporally located in the past [58]. Therefore, they do not capture the daily experiences of ongoing traumatic stress with an absence of safe spaces in which to find protection and experience recovery [59]. Diamond et al., proposed the term 'Ongoing Traumatic Stress Response' (OTSR) which relates to the accumulated effect of ongoing exposure by which anxiety symptoms develop gradually over time as a cumulative result of ongoing exposure to threat [60]. Nuttman-Schwartz \& ShovalZuckerman state that "supplementary frameworks are needed to understand the psychological impact of living with ongoing exposure to danger, as well as appropriate intervention strategies for coping with life in a reality of persistent violence." [61] (p.2). To Kaminer et al., treatment protocols should be more sensitive when treating patients exposed to ongoing conflict, keeping in mind that stress symptoms stem from either direct or indirect exposure from the past, as well as from potential injury from future traumatic events [62].

Jarero \& Artigas have argued that from a memory network's perspective (patterns of associated memories) acute trauma situations are related not only to a time frame (days, weeks, or months) but also to a post-trauma safety period [63]. In their clinical case conceptualization based on the AIP model, they assert that for individuals living historical trauma with ongoing traumatic events in which there is not a post-trauma safety window for traumatic memory consolidation, the consolidation (transition from short to long-term memory) of the traumatic memory is prevented [64-66]. Therefore, the continuum of external traumatic events creates a cumulative trauma exposure memory network of linked pathogenic memories with similar emotional, somatic, sensorial, and cognitive information, that does not give the cumulative state-dependent traumatic memory network sufficient time to consolidate into an integrated whole [67-69]. Thus, this network of linked pathogenic memories remains in a permanent excitatory state as a short-term memory, expanding with each subsequent traumatic event (analogous to the ripple effect of a pebble thrown into a pond), extending into the present moment, often producing maladaptive/catastrophic concerns about the future or flash-forwards [70]. They believe that this type of ongoing traumatic stress situation requires a different kind of EMDR treatment approach than that used for events that have a posttrauma safety period [71-74]. Therefore, Jarero et al., adapted the EMDR-IGTP to treat older children, adolescents, and adults living (like the refugees) with ongoing traumatic stress with no posttrauma safety period for memory consolidation and then developed the EMDR-IGTP Adapted for Ongoing Traumatic Stress (EMDR-IGTP-OTS) [75-79]. The discussion of previous EMDR therapy studies with refugees is beyond the scope of this paper. Therefore, readers will find those studies in the following references [54-56, 80-84].

\section{Objective}

The objective of the study was to evaluate the effectiveness of the EMDR-IGTP-OTS in reducing severe posttraumatic stress disorder, depression, and anxiety symptoms in refugee minors living in Valencia, Spain.

\section{Method}

\subsection{Study Design}

To measure the effect of the EMDR-IGTP-OTS on the dependent variables PTSD, Anxiety, and Depression, this study used a longitudinal randomized control trial (RCT) study design, comparing treatment and non-treatment control groups. Symptoms of PTSD were measured in three-time points: Time 1 pre-treatment, Time 2 post-treatment, and Time 3 follow-up. Anxiety and depression symptoms were measured at Time 1 pre-treatment and Time 3 follow-up.

\subsection{Ethics and Gold Standards}

The research protocol was reviewed and approved by the Autonomous Community of Valencia General Board for the Protection of Childhood and Adolescence IRB in compliance with the International Committee of Medical Journal Editors recommendations, the Guidelines for Good Clinical Practice of the European Medicines Agency (version 1 December 2016) and the Helsinki Declaration as revised in 2013. The research quality of this study was based on the Revised Gold Standard scale items [85]. These include: (a) target symptoms were clearly defined, (b) measures were reliable and valid, 
(c) not blind independent evaluators collected posttreatment measures at Times 2 and 3. Posttreatment measures were collected by blind research assistants; (d) assessor reliability was checked, (e) treatment was manualized, (f) blind random assignment was conducted, (g) treatment fidelity was not evaluated by supervisors. However, treatment fidelity and adherence to the protocol was fulfilled by EMDR therapists' strict observance to all steps of the scripted protocol, (h) no conditions were confounded, (i) multimodal measures were not used, and (j) length of treatment was appropriate for civilian participants with single trauma (five or more sessions).

\subsection{Participants}

This study was conducted in 2019 in the city of Valencia, Spain, in six refugee sites (homes or residences). 196 potential participants were recruited. of those, four participants reached the adult's age and left the residence, and eight participants did not want to participate in the study. A total of 184 refugee minors participated in the research project explanation, attended the intake interview, and fulfilled the inclusion criteria.

Inclusion criteria were: (a) Being legally a minor (under 17 years old), (b) being a refugee living in one of the sites for refugees in Valencia, (c) voluntarily participating in the study, (d) not receiving specialized trauma therapy, (e) not receiving drug therapy for posttraumatic stress disorder symptoms.
Exclusion criteria were: (a) ongoing self-harm/suicidal or homicidal ideation, (b) diagnosis of schizophrenia, psychotic or bipolar disorder, (c) diagnosis of dissociative disorder, (d) organic mental disorder, (e) a current, active chemical dependency problem, (f) significant cognitive impairment (e.g., severe intellectual disability, dementia), (g) presence of uncontrolled symptoms due to medical illness.

A total of 184 minors (all males) met the inclusion criteria. Participants' age ranged from 13 to 17 years old $(\mathrm{M}=16.36$ years). Participants' time since the arrival to the sites in Valencia varied from January 2018 to March 2019. Participation was voluntary, with the consent of both the participants and their legal guardians.

\subsection{Randomization and Blinding Procedure}

Participants were randomly assigned on a 1:1 basis to a treatment group or non-treatment control group using a computer-generated random-number list. Two independent assessors blind to treatment conditions conducted the randomization process to avoid allocation influence. Participants were informed in person if they belonged to the treatment group or the control group. Patients in the non-treatment control group were informed that, for ethical reasons, they would receive the treatment after the study was concluded. The randomization group allocation was masked to the research assistants in charge of the assessments. There were 93 participants in the treatment group and 91 participants in the control group. See Flow Diagram in Figure 1.



Figure 1. Flow Diagram. 


\subsection{Instruments}

1) We used the Posttraumatic Stress Disorder Checklist for DSM-5 (PCL-5) provided directly by the National Center for PTSD (NCPTSD) and adapted, with the NCPTSD approval, the time interval for symptoms to be the past week instead of the past month, due to the high mobility of this population [86-87]. The instrument was translated and back-translated to Arab and French. It contains 20 items, including three new PTSD symptoms (compared with the PTSD Checklist for DSM-IV) [88]: blame, negative emotions, and reckless or self-destructive behavior. Respondents indicate how much they have been bothered by each PTSD symptoms over the past week (rather than the past month), using a 5-point scale ranging from $0=$ not at all, $1=\mathrm{a}$ little bit, $2=$ =moderately, $3=$ quite a bit and $4=$ extremely. A total symptoms score of zero to 80 can be obtained by summing the items. The sum of the scores yields a continuous measure of PTSD symptom severity for symptom clusters and the whole disorder. Psychometrics for the PCL-5, validated against the ClinicianAdministered PTSD Scale-5 (CAPS-5) diagnosis, suggest that a score of 31-33 is optimal to determine probable PTSD diagnosis [89], and a score of 33 is recommended for use at present.

The PCL-5 is intended for a variety of clinical and research assessment tasks, including quantifying PTSD symptom severity, measuring the underlying construct of PTSD, establishing a provisional PTSD diagnosis, and estimating the presumed prevalence of PTSD. Decision rules for PTSD diagnosis based on PCL-5 are very accurate compared to CAPS results. In a recent study, results revealed that veterans who meet core symptoms on the PCL-5 were over 2 times more likely (odds ratio $[\mathrm{OR}]=2.5,95.0 \% \mathrm{CI}$ $[1.68,3.87])$ to meet CAPS-5 diagnosed PTSD than veterans who met the core criteria on the PCL-5 but did not meet CAPS-5 diagnosed PTSD [90]. It is important to mention that at the first assessment meeting, before answering the PCL-5, all participants were asked to focus specifically on the worst refugee-related event that currently bothered them the most; then at each subsequent assessment meeting, they were asked to focus on the same event.

2) The Hospital Anxiety and Depression Scale (HADS) has been extensively used to evaluate these psychiatric comorbidities in various clinical settings at all levels of healthcare services and with the general population [91-92]. The instrument was translated and back-translated to Arab and French. It is a 14 item self-report scale to measure the anxiety (7 items) and depression (7 items) of patients with both somatic and mental problems using a 4-point Likert scale ranging from 0 to 3 . The response descriptors of all items are Yes, definitely (score 3); Yes, sometimes (score 2); No, not much (score 1); No, not at all (score 0). A higher score represents higher levels of anxiety and depression: a domain score of 11 or greater indicates anxiety or depression; 8-10 indicates borderline case; 7 or lower indicates no signs of anxiety or depression.

\subsection{Procedure}

\subsubsection{Cultural Sensitivity, Assessments Times, Blind Data Collection, and Confidentiality of Data}

The refugee sites in Valencia has cultural mediators. They play an important role in the refugee's life because they share their language, religious, and cultural backgrounds. Refugee minors feel secure and have a positive attachment to them. Therefore, before the intervention, EMDR clinicians engaged in a culturally sensitive approach toward the participant's customs and heritage with the cultural mediator's support. All interviews, assessments, and protocol administrations were conducted in the refugee's language with the help of the cultural mediators. To decrease any possible prejudice against the treatment or perceived need for treatment because they are "insane," severity of symptoms was not an inclusion or exclusion criterion. Also, research assistants provided psychoeducation about trauma and answered participants' questions related to trauma, PTSD, anxiety, depression, and EMDR therapy.

Treatment and control group participants completed the instruments -translated to their languages- on an individual basis in the different measurement moments. During time 1, mental health professionals assigned to each site conducted the intake interview, collected clinical histories, and signed informed consent forms from the participants and their legal guardians. Application of instruments for both groups was done after this procedure by research assistants who were not blind to the study but blind to the treatment allocation. During Time 2 (post-treatment assessment) and Time 3 (follow-up assessment 90 days after treatment) assessment was conducted for all participants by research assistants blind to treatment allocation.

All data was collected, stored, and handled in full compliance with the Autonomous Community of Valencia General Board for the Protection of Childhood and Adolescence IRB requirements to ensure confidentiality. The legal guardians of each study participant gave their consent for access to their personal data, which was strictly required for study quality control. All persons involved in this research project were subject to professional confidentiality.

\subsubsection{Withdrawal from the Study}

All research participants had the right to withdraw from the study without justification at any time and with assurances of no prejudicial result. If participants decided to withdraw from the study, they were no longer followed up in the research protocol. There were 33 withdrawals from this study. See Flow Diagram in Figure 1.

\subsubsection{Treatment}

In this study, intensive EMDR therapy was provided [93-94]. Evidence suggests that more frequent scheduling of treatment sessions maximized PTSD treatment outcomes [95]. This intensive format allowed the participants to complete the full course of treatment in a short period. Participants in the 
treatment group completed a total of nine treatment sessions provided during three consecutive days three times a day.

Therapists and Treatment Fidelity

EMDR-IGTP-OTS was provided by eighteen licensed EMDR clinicians formally trained in the protocol administration. To protect the identity of the minors, no videotape or pictures were allowed. Treatment fidelity and adherence to the protocol was fulfilled by the EMDR therapists' strict observance to all steps of the scripted protocol.

EMDR-IGTP-OTS Treatment Description and Tolerance.

An individual history-taking and assessment session was conducted for each potential group member to determine their suitability and readiness for EMDR treatment, following standard procedures. Treatment was provided simultaneously by eighteen licensed EMDR clinicians formally trained in the protocol administration, divided into six teams. Each of the treatment group participants received an average of eight hours of treatment provided during nine group treatment sessions, three times daily during three consecutive days in a setting inside the six refugee sites. EMDR-IGTP-OTS treatment focused only on the distressing memories related to their life as refugees and did not address any other memories. During this process, participants followed directions from the team leader and worked quietly and independently on their distressing memories. First treatment session lasted an average of 95 minutes. Subsequent treatment sessions lasted an average of 48 minutes. Time for rest between sessions lasted an average of one hour and forty minutes. Activities during rest time included sports (i.e., football, walking) or resting after lunch.

To encompass the whole ongoing traumatic stress spectrum, the team leader asked each of the participants to "run a mental movie of everything that happened just before their lives as refugees until now, or even looking into the future." The initial treatment target was the most distressing moment in the mental movie. In subsequent sessions, the team leader asked patients to run the mental movie again and then to target any memory that it is currently disturbing, noticing associated emotions and body sensations. Participants in this study used the Butterfly Hug (BH) 54 times as a self-administered bilateral stimulation method to process traumatic material. During the $\mathrm{BH}$, patients were instructed to stop when they felt in their body that it had been enough. This instruction allowed for enough sets of bilateral stimulation (BLS) for processing the traumatic material and helped to regulate the stimulation to maintain the patients in their window of tolerance allowing for appropriate reprocessing [96-97]. All participants reprocessed more than one memory. No adverse effects were reported during treatment or at the three months post-treatment assessment.

Examples of Worst Experiences Reprocessed During

\section{Treatment}

Generally, the worst experiences that the adolescents reprocessed were related to their boat trip to reach Spain. In many cases, the engine of the small boat was stopped in the middle of the sea, and the sea was very rough, or the boat was turned over, and they did not know if they were going to survive. In other cases, the worst experience was suffering the death of a relative or friend during the journey or finding out about the death of one of their parents once they were already in the care sites. Other participants reported seeing many dead during their trip while spending nights on the street while others reported being beaten by police in various countries. Another worst experience participant reported was when they had to say goodbye to their mother or acknowledging that they ran away without their relatives knowing anything. Others reprocessed flash-forward experiences related to their uncertainty towards the future in the absence of documentation, especially among those who are close to the legal age of majority, because they will have to leave the refugee site at that time.

\section{Statistical Analysis}

Statistical analysis was conducted for those participants, in both treatment $(\mathrm{N}=30)$ and control $(\mathrm{N}=33)$ groups, who completed pre-post-treatment and follow-up assessments and showed clinical symptoms severity. Analyses of variance (ANOVA) for repeated measurements was used for PTSD, Anxiety, and Depression; t-test and Cohen's $d$ effect size was calculated using within and between designs for the different measurements.

\section{Results}

PTSD (PCL-5). Data analysis by repeated measures ANOVA revealed a significant effect for time $(F(2,122)=$ $\left.43.17 \mathrm{p}<.001, \eta_{P}{ }^{2}=.414\right)$, a significant effect for group ( $\mathrm{F}(1$, $\left.61=5.52, \mathrm{p}<.05, \eta_{P}{ }^{2}=.898\right)$ and a significant interaction between time and group, $\left(\mathrm{F}(2,122)=11.10, \mathrm{p}<.001, \eta_{P}{ }^{2}\right.$ $=.154$ ). In the treatment group, mean scores showed a significant decrease with a large effect between time 1 and time $2, \mathrm{t}(29)=5.22, \mathrm{p}<.001, d=.81$ There was also a significant decrease between time 1 to time $3, \mathrm{t}(29)=$ 2.66.25, $\mathrm{p}<.01, d=.29$. In the control group no significant differences were found between means in all comparisons. Comparison between groups did not show significant differences for time 1 . For time 2 and for time 3 significant differences among the groups were founded, $\mathrm{t}(61)=-2.16, \mathrm{p}$ $<.05, d=.54$ and $\mathrm{t}(61)=-3.50, \mathrm{p}<.001, d=.88$, respectively. See Table 1 and Figure 2.

Table 1. Mean scores (M) and standard deviations (SD) for treatment and non-treatment group on pretest, posttest and follow up measurements.

\begin{tabular}{lllllll}
\hline & \multicolumn{1}{c}{ Time 1 } & Time 2 & \multicolumn{2}{c}{ Time 3 } \\
\cline { 2 - 7 } & M & SD & M & SD & M & SD \\
\hline Posttraumatic Stress (PCL-5) & & & & & & \\
Treatment group & 45.96 & 10.87 & 27.43 & 19.89 & 20.26 & 14.19 \\
Non treatment group & 42.06 & 8.69 & 37.42 & 16.69 & 33.09 & 14.81 \\
Anxiety & & & & & & \\
\hline
\end{tabular}




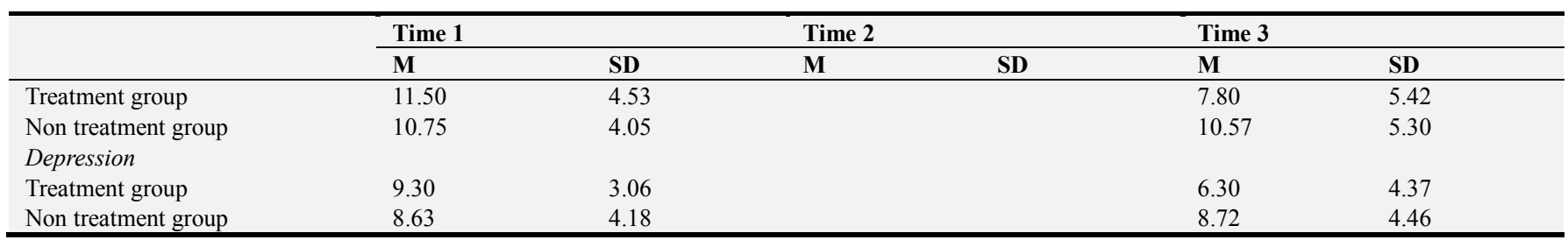

\section{PCL5}

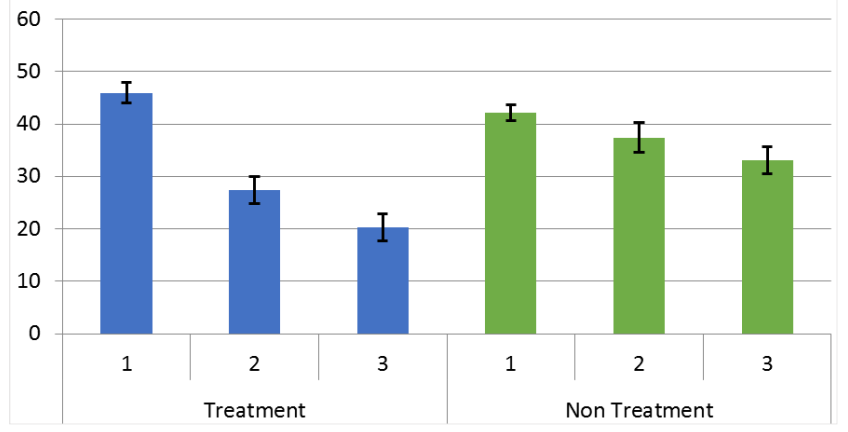

Figure 2. Mean scores and standard error for PCL-5 by time and group.

Anxiety. Repeated measures analysis of variance (ANOVA) for anxiety showed a significant effect for time $(\mathrm{F}$ $\left.(1,61)=7.46, \mathrm{p}<.001, \eta_{P}^{2}=.109\right)$ and a significant interaction effect between time and group $(\mathrm{F}(1,61)=6.13, \mathrm{p}$ $\left.<.01, \eta_{P}{ }^{2}=.091\right)$. No significant effect was found for group. Significant differences between the two measurements were found for the treatment group, $\mathrm{t}(29)=3.21 .49, \mathrm{p}<.005, d$ $=.52$. No significant differences were observed in the nontreatment control group between different time applications. Comparison between groups showed significant differences in the post evaluation for this variable, $\mathrm{t}(61)=-2.05, \mathrm{p}<.05$, $d=.51$. See Table 1 and Figure 3 .

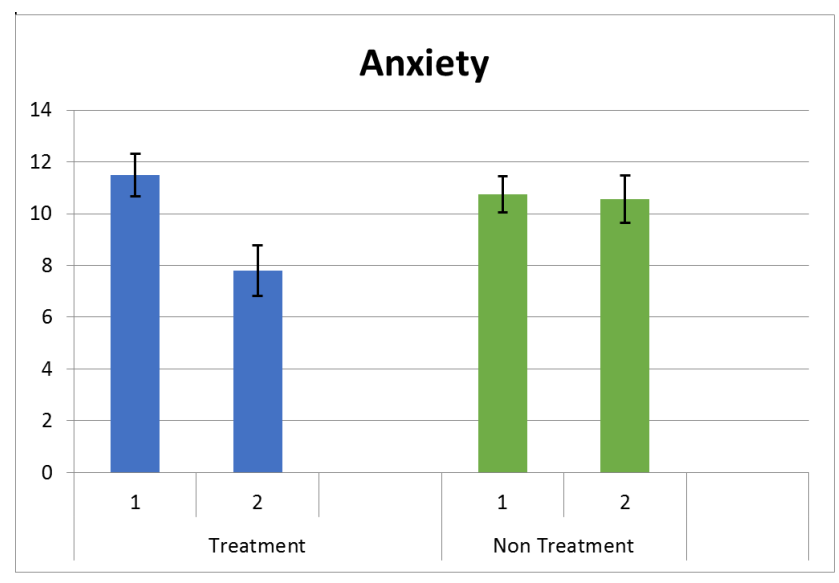

Figure 3. Mean scores and standard error for Anxiety by time and group.

Depression. Significant effects were found for time (F (1, $61)=7.02, \mathrm{p}<.01, \eta_{P}^{2}=.104$. Results also showed significant interaction effects between time and group. (F (1, $\left.61)=7.92, \mathrm{p}<.001, \eta_{P}{ }^{2}=.116\right)$. No significant effects for group were founded. For the treatment group significant differences were found between the two measurements, $t$ (29) $=3.62, \mathrm{p}<.001, d=.75)$. About control group, no significant differences were found. Comparison between groups showed significant differences in the second measure of this variable $2, \mathrm{t}(61)=-2.17, \mathrm{p}<.05, \mathrm{~d}=.54$. See Table 1 and Figure 4 .

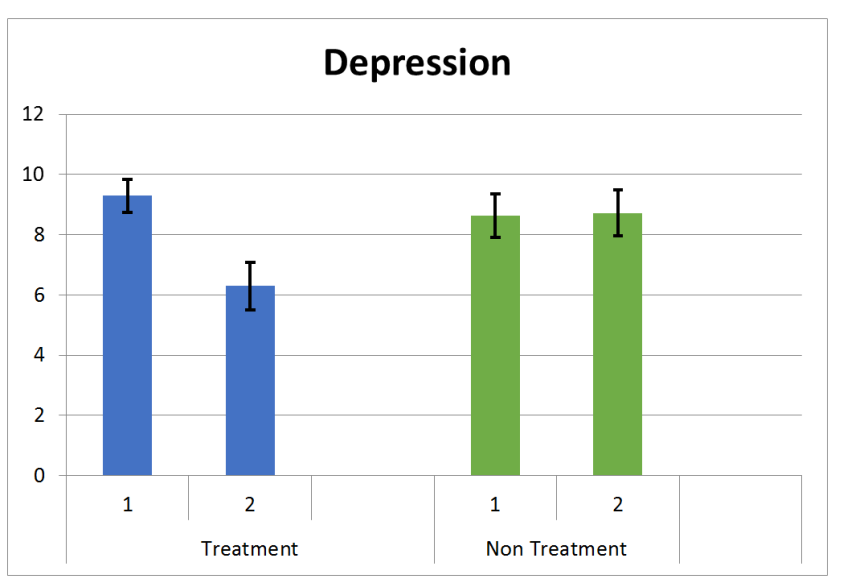

Figure 4. Mean scores and standard error for Depression by time and group.

\section{Discussion}

The aim of this longitudinal multisite randomized controlled trial was to evaluate the effectiveness of the EMDR-IGTP-OTS in reducing severe posttraumatic stress disorder, depression, and anxiety symptoms related to the refugee-life experience. This study was conducted in 2019 in the city of Valencia, Spain, in six refugee sites. A total of 184 minors (all males) met the inclusion criteria. Participants ranged in age from 13 to 17 years old ( $\mathrm{M}=16.36$ years). There were 93 participants in the treatment group and 91 participants in the control group. Statistical analysis was conducted for those participants, in both treatment $(\mathrm{N}=30)$ and control $(\mathrm{N}=33)$ groups, who completed pre-posttreatment and follow-up assessments and showed clinical symptoms severity. No differences were found for age between groups. Data analyses demonstrated significant effects for PTSD, anxiety, and depression in the treatment group while no differences were found, between the different measurements, for the control group. It is important to highlight that strong effects according Cohen's $d$ were found for the treatment group between the first and the second measurement of PTSD as well between the scores comparing in the third measurement compared with the control group, indicating the immediate effect of the EMDR Integrative Group Treatment Protocol for Ongoing Traumatic Stress. Significant effects were also observed for anxiety and depression in the treatment group, without observing changes for the control group.

Mental health problems among refugees are an important 
global health issue. Empirical studies conducted with refugees of very different ethnic background have shown that PTSD, depression, and attachment trauma in children could be common in this population, both among internally displaced people and in refugees settled in foreign countries [98-100]. Cumulative trauma exposes this population to a higher risk of mental health problems and undermines their psychosocial recovery [101-102]. We believe that the EMDR-IGTP-OTS could be an auspicious answer to cope with these problems and to escalate the benefits of EMDR therapy to communities, families, and groups because it incorporates many advantages that are suitable for the refugee population. The protocol allows for the identification, targeting, and processing of the continuum of multiple traumatic experiences faced by refugee populations who are experiencing ongoing traumatic stress.

Individual EMDR treatment can be provided in a group setting to small or large groups of patients in an intensive treatment modality so that patients can receive efficient and effective treatment. All treatment and memory exposure takes place in the affect-regulating presence of the therapists. As a cross-cultural treatment with cultural sensitivity [54], EMDRIGTP-OTS reduces cultural resistance to treatment, even to members of reticent cultures, because it is minimally intrusive, and does not require creating a narrative of the traumatic experience, verbal or written disclosure of details, the prolonged reliving of traumatic experiences, or homework. The disturbing memory is not visualized mentally as in the standard EMDR protocol but instead is represented concretely in the participant's drawings or symbols. Drawing is superior to activities such as reading or writing because it forces the person to process information in multiple ways: visually, kinesthetically, and semantically. Drawing also promotes the integration of elaborative, pictorial, and motor codes, facilitating the creation of a context-rich representation [103]. Relying on drawings or symbols presents a special advantage to provide culturally sensitive and effective treatment for patients who struggle to connect to their cognitive states or feel guilty or ashamed, they may be more comfortable expressing their emotional distress through drawing. Also, drawings are used for effective reprocessing with patients with lower levels of literacy like the participants in this study [104].

\section{Conclusion, Limitations, and Future Directions}

Refugees' ongoing traumatic exposure to intense threat, war, and terror has been linked to higher levels of stress symptoms, PTSD, and depression with a great risk for psychopathology. Mental health professionals have the responsibility to help refugees in urgent need of humanitarian mental health care to prevent or overcome psychological hazards. The study results indicate that the intensive administration of the EMDR-IGTP-OTS could be a feasible, cost-effective, time-efficient, culturally sensitive, and effective component of a multidisciplinary psycho-social group-based program to address PTSD, depression, and anxiety symptoms among refugee minors.

We would like to share Dr. Francine Shapiro's (EMDR therapy originator) message to the EMDR clinicians involved in this study: "Dear Nacho, please give my thanks and best wishes to all of the clinicians involved in the study. This RCT can provide the basis for treatment and the alleviation of suffering worldwide. Millions of people will be affected for many years to come. Butterfly Hugs. Francine Shapiro." (Personal communication, April 12, 2019)

Besides the multiple strengths of this study, a limitation is the lack of a formal diagnosis of PTSD in the research population, the 90-days follow-up, and only one gender population (males). We recommend randomized controlled trials using an instrument to conduct formal PTSD diagnosis (e.g., CAPS-5), with follow-up at six or twelve months when possible to evaluate the long-term effect in both male and female participants.

\section{Conflict of Interest and Founding}

The authors declare that they have no competing interest.

\section{Acknowledgements}

All the EMDR clinicians that participated in this study want to express their gratitude to Dr. Francine Shapiro $₫$ for her legacy and personal support to this research project. Also, they express their gratitude to the staff at all the refugee sites (directors, deputy directors, social workers, psychologist, cultural mediators, and teachers). Francisca García, Olga Fernández-García, Miguel Fuster Almarche, María José Fuster, Milagros Molero, Ana Lucila Soto Rubio, Nuria López Vilaplana, María Rosario Lorenzo Moreno, Rosario Bustamante Navarro, María Nieves Acha Durán, Francesc Giner, María José Carrillo Sánchez, Gloria Sánchez Almarcha, Rosa Valero García, Sara García Cabezas, María Encarnación Terrez Ruíz, Nuria Perez Gonzalez, Lourdes Estrella Tello, Cristina Cortés, Anabel de la Cruz, Fernando Monfort, Anabel Gonzalez, and Lynne Levinson.

\section{References}

[1] Lambert, J. E., \& Alhassoon, O. M. (2014). Trauma-focused therapy for refugees: Meta-analytic findings. Journal of Counseling Psychology, 62, 28-37.

[2] United Nations High Commissioner for Refugees (2018). Global Trends. Force Displacement in 2017. Retrieved at https://www.unher.org/globaltrends2017/

[3] Autonomous Community of Valencia General Board for the Protection of Childhood and Adolescence. Personnal Communication. Jun 18, 2019.

[4] Bogic, M., Njoku, A., \& Priebe, S. (2015). Long-term mental health of war-refugees: a systematic literature review. $B M C$ International Health and Human Rights, 15 (1), 29. http://doi.org/10.1186/ s12914-015-0064-9 
[5] Nickerson, A., Bryant, R. A., Silove, D., \& Steel, Z. (2011). A critical review of psychological treatments of posttraumatic stress disorder in refugees. Clinical Psychology Review, 31, 399-417. doi: 10.1016/j.cpr.2010.10.004.

[6] Kulla, M., Josse, F., Stierholz, M., Hossfeld, B., Lampl, L., \& Helm, M. (2016). Initial assessment and treatment of refugees in the Mediterranean Sea (a secondary data analysis concerning the initial assessment and treatment of 2656 refugees rescued from distress at sea in support of the EUNAVFOR MED relief mission of the EU). Scandinavian Journal of Trauma Resuscitation and Emergency Medicine, 24, 75. doi: 10.1186/s13049-016-0270-z.

[7] Allan, J. (2015). Reconciling the 'psycho-social/structural' in social work counselling with refugees. British Journal of Social Work, 45, 1699-1716. doi: 10.1093/bjsw/bcu051.

[8] Goodkind, J. R., Hess, J. M., Isakson, B., LaNoue, M., Githinji, A., Roche, N., Parker, D. P. (2014). Reducing refugee mental health disparities: A community-based intervention to address postmigration stressors with African adults. Psychological Services, 11, 333-346. doi: 10.1037/a0035081

[9] Rasmussen, A., Nguyen, L., Wilkinson, J., Vundla, S., Raghavan, S., Miller, K. E., \& Keller, A. S. (2010). Rates and impact of trauma and current stressors among Darfuri refugees in eastern Chad. American Journal of Orthopsychiatry, 80, 227-236. doi: 10.1111/j.1939-0025.2010.01026.x.

[10] Slobodin, O., \& de Jong, J. T. (2015). Mental health interventions for traumatized asylum seekers and refugees: What do we know about their efficacy? The International Journal of Social Psychiatry, 61, 17-26. doi: $10.1177 / 0020764014535752$.

[11] Palic, S., \& Elklit, A. (2011). Psychosocial treatment of posttraumatic stress disorder in adult refugees: A systematic review of prospective treatment outcome studies and a critique. Journal of Affective Disorders, 131, 8-23. doi: 10.1016/j.jad.2010.07.005.

[12] Chung, M. C., Shakra, M., AlQarni, N., AlMazrouei, M., Al Mazrouei, S., \& Al Hashimi, S. (2018). Posttraumatic Stress Among Syrian Refugees: Trauma Exposure Characteristics, Trauma Centrality, and Emotional Suppression. Psychiatry, 117. http://doi.org/10.1080/0033274 7.2017.1354620

[13] Tinghög, P., Malm, A., Arwidson, C., Sigvardsdotter, E., Lundin, A., \& Saboonchi, F. (2017). Prevalence of mental ill health, traumas and postmigration stress among refugees from Syria resettled in Sweden after 2011: a population-based $\begin{array}{llll}\text { survey. } \quad B M J & \text { Open, } & \text { e18899. }\end{array}$ http://doi.org/10.1136/bmjopen-2017-018899

[14] United Nations High Commissioner for Refugees (UNHCR). (2004). Statistical yearbook. Geneva, Switzerland: United Nations.

[15] American Psychiatric Association. (2013). Diagnostic and statistical manual of mental disorders $\left(5^{\text {th }} \mathrm{ed}\right.$.). Arlington, VA.

[16] Shapiro, F. (2018). Eye movements desensitization and reprocessing. Basic principles, protocols, and procedures (Third edition). Guilford Press.

[17] World Health Organization. (2013). Guidelines for the management of conditions specifically related to stress. Geneva, Switzerland: Author.
[18] Jarero, I., \& Artigas, L. (2009). EMDR integrative group treatment protocol. Journal of EMDR Practice \& Research, 3 (4), 287-288.

[19] Artigas, L., \& Jarero, I. (2014). The Butterfly Hug. In M. Luber (Ed.). Implementing EMDR Early Mental Health Interventions for Man-Made and Natural Disasters (pp. 127130). New York, NY: Springer.

[20] Artigas, L., Jarero, I., Alcalá, N., \& López Cano, T. (2014). The EMDR Integrative Group Treatment Protocol (IGTP) for children. In M. Luber (Ed.), Implementing EMDR early interventions for man-made and natural disasters (pp. 237251). New York, NY: Springer Publishing.

[21] Jarero, I., \& Artigas, L. (2014). The EMDR Integrative Group Treatment Protocol (IGTP) for Adults. In M. Luber (Ed.). Implementing EMDR Early Mental Health Interventions for Man-Made and Natural Disasters (pp. 253-265). New York, NY: Springer.

[22] Adúriz, M. E., Knopfler, C., \& Bluthgen, C. (2009). Helping child flood victims using group EMDR intervention in Argentina: Treatment outcome and gender differences. International Journal of Stress Management, 16 (2), 138-153.

[23] Yalom, I. D. (1970). The theory and practice of group psychotherapy. New York, NY: Basic Books.

[24] Deblinger, E., \& Pollio, E. (2013). Implementing trauma focused cognitive behavioral therapy (TF-CBT) in a group format. Retrieved from http://www.cpe.rutgers.edu/njdcf2013/docs/008

[25] Gelbach, R., \& Davis, K. (2007). Disaster response: EMDR and family systems therapy under communitywide stress. In F. Shapiro, F. W. Kaslow, \& L. Maxfield (Eds.), Handbook of EMDR and family therapy processes (pp. 387-406). New York, NY: Wiley.

[26] Maxfield, L. (2008). EMDR treatment of recent events and community disasters. Journal of EMDR Practice \& Research, $2(2), 74-78$.

[27] Jarero, I., \& Artigas, L. (2012). The EMDR Integrative Group Treatment Protocol: EMDR group treatment for early intervention following critical incidents. European Review of Applied Psychology, 62, 219-222.

[28] Jarero, I., Artigas., Uribe, S., Miranda, A. (2014). EMDR Therapy Humanitarian Trauma Recovery Interventions in Latin America and the Caribbean. Journal of EMDR Practice and Research, 8 (4), 260-268.

[29] Luber, M. (2009). EMDR and early interventions for groups. In M. Luber (Ed.), Eye movement desensitization and reprocessing (EMDR) scripted protocols: Basic and special situations (pp. 277-278). New York, NY: Springer Publishing.

[30] Luber, M \& Shapiro, F. (2009). Interview with Francine Shapiro: historical overview, present issues, and future directions of EMDR. Journal of EMDR Practice and Research $3(4), 217-231$.

[31] Artigas, L., Jarero, I., Mauer, M., López Cano, T., \& Alcalá, N., 2000. EMDR and traumatic stress after natural disasters: integrative treatment protocol and the butterfly hug. Poster presented at the EMDRIA Conference, September, Toronto, Ontario, Canada. 
[32] Jarero, I., Artigas, L., Mauer, M., López Cano, T., \& Alcalá, N. (1999, November). Children's post-traumatic stress after natural disasters: Integrative treatment protocol. Poster session presented at the annual meeting of the International Society for Traumatic Stress Studies, Miami, FL.

[33] Jarero, I., Artigas, L., \& Hartung, J. (2006). EMDR integrative treatment protocol: A post-disaster trauma intervention for children \& adults. Traumatology, 12, 121-129.

[34] Adúriz, M. E., \& Salas, C. (2014). Aplicación del Protocolo Grupal e Integrativo con EMDR a las Víctimas de un Alud en Tartagal-Salta-Argentina. Revista Iberoamericana de Psicotraumatología y Disociación, 6 (2), 1-12. ISSN: 2007-8544.

[35] Aránguiz, I \& Cattoni, M. (2013). Psicoterapia Grupal en Pacientes con Trauma Reciente: Una propuesta integradora desde el modelo EMDR. Fortaleciendo Redes: Experiencia con EMDR en la superación de un evento crítico. Mutual de Seguridad. Chile.

[36] Monteiro, A. (2014). Group and Individual EMDR therapy in the Humanitarian Assistance Project in Southern Brazil. Iberoamerican Journal of Psychotraumatology and Dissociation, 6 (3), 1-19. ISSN: $2007-8544$. www.revibapst.com

[37] Salas, C. (2014). Aplicación del Protocolo Grupal e Integrativo con EMDR a las Víctimas de un Alud en Angastaco-Argentina. Iberoamerican Journal of Psychotraumatology and Dissociation, 6 (2), 1-11. ISSN: 2007-8544. www.revibapst.com

[38] Mehrotra, S., Purandare, M., Tank, P., \& Bhagwagar, H. (2013). Establishing EMDR connections with earthquake survivors of Gujarat, Western India (2001). In M. Luber (Ed.), Implementing EMDR early mental health interventions for man-made and natural disasters: Models, scripted protocols, and summary sheets (pp. 107-120). New York, NY: Springer Publishing.

[39] Mehrotra, S. (2014). Humanitarian Projects and Growth of EMDR Therapy in Asia. (2014). Journal of EMDR Practice and Research, 8 (4), 252-259.

[40] Korkmazlar-Oral, U., Pamuk, S., (2002). Group EMDR with Child survivors of the earthquake in Turkey. Journal of the American Academy of Child and Adolescent Psychiatry 37, $47-50$.

[41] Jarero, I., Artigas, L., \& Montero, M. (2008). The EMDR integrative group treatment protocol: Application with child victims of a mass disaster. Journal of EMDR Practice and Research, 2 (2), 97-105. DOI: 10.1891/1933-3196.2.2.97.

[42] Fernandez, I., Gallinari, E., \& Lorenzetti, A. (2003). A schoolbased intervention for children who witnessed the Pirelli building airplane crash in Milan, Italy. Journal of Brief Therapy, 2 (2), 129-136.

[43] Maslovaric, G., Zaccagnino, M., Mezzaluna, C., Perilli, S., Trivellato, D., Longo, V., and Civilotti, C. (2017). The Effectiveness of Eye Movement Desensitization and Reprocessing Integrative Group Protocol with Adolescent Survivors of the Central Italy Earthquake. Front. Psychol. 8: 1826. DOI: $10.3389 /$ fpsyg.2017.01826.

[44] Zaghrout-Hodali, M., Alissa, F., \& Dodgson, P. (2008). Building resilience and dismantling fear: EMDR group protocol with children in an area of ongoing trauma. Journal of EMDR Practice and Research, 2 (2), 106-113. DOI:

\section{$10.1891 / 1933-3196.2 .2 .106$}

[45] Jarero, I., \& Artigas, L. (2010). EMDR integrative group treatment protocol: Application with adults during ongoing geopolitical crisis. Journal of EMDR Practice and Research, 4 (4), 148-155. DOI: 10.1891/1933-3196.4.4.148.

[46] Allon, M. (2015). EMDR group therapy with women who were sexually assaulted in the Congo. Journal of EMDR Practice and Research, 9 (1), 28-34.

[47] Wilson, S., Thinker, R., Becker, L., Hofmann, A., \& Kleiner, K. (2000, September). A field study of EMDR with KosovarAlbanian refugee children using a group treatment protocol. Symposium presented at the annual conference of the EMDR International Association, Toronto, Canada.

[48] Jarero, I., Roque-López, S., Gómez, J. (2013). The Provision of an EMDR-Based Multicomponent Trauma Treatment with Child Victims of Severe Interpersonal Trauma. Journal of EMDR Practice \& Research, 7 (1), 17-28.

[49] Jarero, I., Roque-López, S., Gómez, J., Givaudan, M. (2014a). Second Research Study on the Provision of the EMDR Integrative Group Treatment Protocol with Child Victims of Severe Interpersonal Violence. Iberoamerican Journal of Psychotraumatology and Dissociation, 6 (1), 1-24. ISSN: 2007-8544. www.revibapst.com

[50] Jarero, I., Roque-López, S., Gómez, J., Givaudan, M. (2014b). Third Research Study on the Provision of the EMDR Integrative Group Treatment Protocol with Child Victims of Severe Interpersonal Violence. Iberoamerican Journal of Psychotraumatology and Dissociation, 6 (2), 1-22. ISSN: 2007-8544. www.revibapst.com

[51] Jarero, I., Rake, G., \& Givaudan, M. (2017). EMDR Therapy Program for Advance Psychosocial Interventions Provided by Paraprofessionals. Journal of EMDR Practice and Research, 11 (3), 122-128. DOI: 10.1891/1933-3196.11.3.122.

[52] Passoni, S., Curinga, T., Toraldo, A., Berlingeri, M., Fernandez, I., Bottini, G. (2018). Eye Movement Desensitization and Reprocessing Integrative Group Treatment Protocol (EMDR-IGTP) applied to caregivers of patients with dementia. Frontiers in Psychology, Vol. 9. Article 967. DOI: 10.3389/fpsyg.2018.00967.

[53] Harris, H., Urdaneta, V., Triana, V., Vo, C. S., Walden, D., Myers, D. (2018). A Pilot Study with Spanish-Speaking Latina Survivors of Domestic Violence Comparing EMDR \& TF-CBT Group Interventions. Open Journal of Social Sciences, 6, 203-222.

[54] Hurn, R., Barron, I. (2018). The EMDR Integrative Group Treatment Protocol in a Psychosocial Program for Refugee Children: A Qualitative Pilot Study. Journal of EMDR Practice and Research, 12 (4), 208-223.

[55] Perilli, S., Giuliani, A., Pagani, M., Mazzoni, G. P., Maslovari, G., Maccarrone, B., Morales, D. (2019). EMDR Group Treatment of Children Refugees -A Feasibility Field Study. Journal of EMDR Practice and Research, 13 (3), 143-155.

[56] Smyth-Dent, K. L., Fitzgerald, J., Hagos, Y. (2019). A Field Study on the EMDR Integrative Group Treatment Protocol for Ongoing Traumatic Stress Provided to Adolescent Eritrean Refugees Living in Ethiopia. Psychology and Behavioral Science International Journal, 12 (4), 1-12. 
[57] Marie-Jo Brennstuhl, Fanny Bassan, Anne-Marie Fayard, Mathieu Fisselbrand, Amandine Guth, Maud Hassler, Karen Lebourg, Rachel Pavisse, Lydia Peter, Adeline Thiriet, Pascale Tarquinio, Jenny Ann Rydberg, Cyril Tarquinio. (2019). Immediate treatment following the November 13 attacks: Use of an EMDR emergency 1. European Journal of Trauma and Dissociation, 3, 17-21.

[58] Stevens, G., Eagle, G., Kaminer, D., \& Higson-Smith, C. (2013). Continuous traumatic stress: Conceptual conversations in contexts of global conflict, violence and trauma. Peace and Conflict: Journal of Peace Psychology, 19, 75-84.

[59] Straker, G. (2013). Continuous traumatic stress: Personal reflections 25 years on. Peace and Conflict: Journal of Peace Psychology, 19, 209-217.

[60] Diamond, G. M., Lipsitz, J. D., Fajerman, Z., Rozenblat, O., 2010. Ongoing traumatic stress response (OTSR) in Sderot, Israel. Prof. Psychol. Res. Pract. 41 (1), 19-25. http://dx.doi.org/10.1037/a0017098

[61] Nuttman-Shwartz \& Shoval-Zuckerman. (2015). Continuous Traumatic Situations in the Face of Ongoing Political Violence: The Relationship Between CTS and PTSD. Trauma, Violence and Abuse, 1-9.

[62] Kaminer, D., Eagle, G., Crawford-Browne, S., 2016. Continuous traumatic stress as a mental and physical health challenge: case studies from South Africa. J. Health Psychol. http://dx.doi.org/10.1177/1359105316642831

[63] Jarero, I., \& Artigas, L. (2018). AIP model-based Acute Trauma and Ongoing Traumatic Stress Theoretical Conceptualization. Iberoamerican Journal of Psychotraumatology and Dissociation, 10 (1), 1-7. www.revibapst.com

[64] Jarero, I., Artigas, L., \& Luber, M. (2011). The EMDR protocol for recent critical incidents: Application in a disaster mental health continuum of care context. Journal of EMDR Practice and Research, 5 (3), 82-94. DOI: 10.1891/19333196.5.3.82.

[65] Jarero, I., \& Uribe, S. (2011). The EMDR protocol for recent critical incidents: Brief report of an application in a human massacre situation. Journal of EMDR Practice and Research, 5 (4), 156-165. DOI: http://dx.doi.org/10.1891/19333196.5.4.156.

[66] Jarero, I., \& Uribe, S. (2012). The EMDR protocol for recent critical incidents: Follow-up Report of an application in a human massacre situation. Journal of EMDR Practice and Research, 6 (2), 50-61. DOI: 10.1891/1933-3196.6.2.50.

[67] Jarero, I., Amaya, C., Givaudan, M., \& Miranda, A. (2013). EMDR Individual Protocol for Paraprofessionals Use: A Randomized Controlled Trial Whit First Responders. Journal of EMDR Practice and Research, 7 (2), 55-64.

[68] Centonze, D., Siracusane, A., Calabresi, P., and Bernardi, G. (2005). Removing pathogenic memories. Mol. Neurobiol. 32, $123-132$.

[69] van der Kolk, B. A., \& van der Hart, O. (1991). The intrusive past: The flexibility of memory and the engraving of trauma. American Imago, 48 (4), 425-454.

[70] Logie, R., \& de Jongh, A. (2014). The "flashforward" procedure: Confronting the catastrophe. Journal of EMDR Practice and Research, 8, 25-32.
[71] Jarero, I., Uribe, S., Artigas, L., Givaudan, M. (2015). EMDR protocol for recent critical incidents: A randomized controlled trial in a technological disaster context. Journal of EMDR Practice and Research, 9 (4), 166-173. DOI: http://dx.doi.org/10.1891/1933-3196.9.4.166.

[72] Jarero, I., Schnaider, S., Givaudan, M. (2019). EMDR Protocol for Recent Critical Incidents and Ongoing Traumatic Stress with First Responders: A Randomized Controlled Trial. Journal of EMDR Practice and Research, 13 (2).

[73] Encinas, M., Osorio, A., Jarero, I., Givaudan, M. (2019). Randomized Controlled Clinical Trial on the Provision of the EMDR-PRECI to Family Caregivers of Patients with Autism Spectrum Disorder. Psychology and Behavioral Science International Journal, $11 \quad$ (1), 1-8, DOI: 10.19080/PBSIJ.2019.11.555802.

[74] Estrada, B. D., Angulo, B. J., Navarro, M. E., Jarero, I., Sánchez-Armass, O. (2019). PTSD, Immunoglobulins, and Cortisol Changes after the Provision of the EMDR- PRECI to Females Patients with Cancer-Related PTSD Diagnosis. American Journal of Applied Psychology, 8 (3), 64-71.

[75] Jarero, I., \& Artigas, L., Uribe, S., García, L, E., Cavazos, M. A., \& Givaudan, M. (2015). Pilot Research Study on the Provision of the EMDR Integrative Group Treatment Protocol with Female Cancer Patients. Journal of EMDR Practice and Research, 9 (2), 98-105.

[76] Jarero, I., Artigas, L., Uribe, S., García. L. E. (2016). The EMDR Integrative Group Treatment Protocol for Patients with Cancer. Journal of EMDR Practice and Research, 10 (3), 199207.

[77] Jarero, I., Givaudan, M., Osorio, A. (2018). Randomized Controlled Trial on the Provision of the EMDR Integrative Group Treatment Protocol Adapted for Ongoing Traumatic Stress to Patients with Cancer. Journal of EMDR Practice and Research, 12 (3), 94-104. http://dx.doi.org/10.1891/19333196.12.3.94.

[78] Osorio, A., Pérez, M. C., Tirado, S. G., Jarero, I., Givaudan, M. (2018). Randomized Controlled Trial on the EMDR Integrative Group Treatment Protocol for Ongoing Traumatic Stress with Adolescents and Young Adults Patients with Cancer. American Journal of Applied Psychology, 7 (4), 50-56. doi: 10.11648/j.ajap.20180704.11.

[79] Wong, S-L (2018). EMDR-based Divorce Recovery Group: A case study. Journal of EMDR Practice and Research, 12 (2), 58-70. DOI: http://dx.doi.org/10.1891/1933-3196.12.2.58.

[80] Acarturk, C., Konuk, E., Cetinkaya, M., Senay, I., Sijbrandij, M., Cuijpers, P., \& Aker, T. (2015). EMDR for Syrian refugees with posttraumatic stress disorder symptoms: results of a pilot randomized controlled trial. Eur. J. Psychotraumatol. 6: 27414. doi: 10.3402/ejpt.v6.27414.

[81] Acarturk, C., Konuk, E., Cetinkaya, M., Senay, I., Sijbrandij, M., Gulen, B., \& Cuijpers, P. (2016). The efficacy of eye movement desensitization and reprocessing for post-traumatic stress disorder and depression among Syrian refugees: results of a randomized controlled trial. Psychol. Med. 46, 25832593. doi: 10.1017/S0033291716001070.

[82] Lehnung, M., Shapiro, E., Schreiber, M., Hofmann, A. (2017). Evaluating the EMDR Group Traumatic Episode Protocol with Refugees: A Field Study. Journal of EMDR Practice and Research, 11 (3), 129, 138. 
[83] Yurtsever, A., Konuk, E., Akyüz, T., Zat, Z., Tükel, F., Çetinkaya, M., Savran, C., Shapiro, E. (2018). An Eye Movement Desensitization and Reprocessing (EMDR) Group Intervention for Syrian Refugees With Post-traumatic Stress Symptoms: Results of a Randomized Controlled Trial Front. Psychol. 9: 493. doi: 10.3389/fpsyg.2018.00493.

[84] Oras R, Cancela de Ezpeleta S, Ahmad A. Treatment of traumatized refugee children with Eye Movement Desensitization and Reprocessing in a psychodynamic context Nord J Psychiatry 2004; 58: 199 -/203. Oslo. ISSN 0803-9488.

[85] Maxfield, L., \& Hyer, L. (2002). The relationship between efficacy and methodology in studies investigating EMDR treatment of PTSD. Journal of Clinical Psychology, 58, 23-41.

[86] Weathers, F. W., Litz, B. T., Keane, T. M., Palmieri, P. A., Marx, B. P., \& Schnurr, P. P. (2013). The PTSD Checklist for DSM-5 (PCL-5). Scale available from the National Center for PTSD at www.ptsd.va.gov.

[87] Bovin MJ, Marx BP, Weathers FW, Gallagher MW, Rodriguez P, et al. (2016) Psychometric properties of the PTSD checklist for diagnostic and statistical manual of mental disorders- Firth edition (PCL-5) in veterans. Psychol Assess 28 (11): 1379-1391.

[88] American Psychiatric Association. (2000). Diagnostic and statistical manual of mental disorders $\left(4^{\text {th }}\right.$ ed. Text Revised). Arlington, VA.

[89] Weathers, F. W., Blake, D. D., Schnurr, P. P., Kaloupek, D. G., Marx, B. P., Keane, T. M., 2013a. Clinician-administered PTSD Scale for DSM-5. National Center for Posttraumatic Stress Disorder, Boston.

[90] Franklin, C., Raines, A. M., Cucurullo, L- A., Chambliss, J. L. Maieritsch, K. P., Tompkins, A. M., Walton, J. L. (2018). 27 ways to meet PTSD: Using the PTSD-checklist for DSM-5 to examine PTSD core criteria. Psychiatry Research 261, 504507. doi.org/10.1016/j.psychres.2018.01.021.

[91] Zigmond, A. S. \& Snaith, R. P. (1983). The Hospital Anxiety and Depression Scale. Acta Psychiatrica Scandinavica, 67, 361-370.

[92] Ying Lin C, Pakpour AH (2017) Using Hospital Anxiety and Depression Scale (HADS) on patients with epilepsy: Confirmatory factor analysis and Rasch models. Seizure (45): 42-46.

[93] Hurley, E. C. (2018). Effective Treatment of Veterans With PTSD: Comparison Between Intensive Daily and Weekly EMDR Approaches. Front. Psychol. 9: 1458. doi: 10.3389/fpsyg.2018.01458.
[94] Bongaerts, H., Van Minnen, A., de Jongh, A. (2017) Intensive EMDR to treat patients with complex posttraumatic stress disorder: A case series. Journal of EMDR Practice and Research, 11 (2), 84-95.

[95] Gutner, C. A., Suvak, M. K., Sloan, D. M., \& Resick, P. A. (2016). Does timing matter? Examining the impact of session timing on outcome. Journal of Consulting and Clinical Psychology, 84, 1108-1115.

[96] Ogden, P., Minton, K., \& Pain, C. (2006). Trauma and the body: A sensorimotor approach to psychotherapy. New York, NY: Norton.

[97] Siegel, D. J. (1999). The developing mind: How relationships and the brain interact to shape who we are. New York, NY: Guilford Press.

[98] Norris, F. H. \& Hamblen, J. L. (2004). Standardized selfreport measures of civilian trauma and PTSD. In J. P. Wilson, T. M. Keane \& T. Martin (Eds.), Assessing psychological trauma and PTSD (pp. 63-102). New York: Guilford Press. PTSD pubs ID 18638.

[99] Fazel, M., Wheeler, J., Danesh, J. (2005) Prevalence of serious mental disorder in 7000 refugees resettled in western countries: A systematic review. Lancet. 365: 1309-1314.

[100] Haslam, P. M. (2005). Predisplacement and postdisplacement factors associated with mental health of refugees and internally displaced persons: A meta-analysis. JAMA. 294: 602-612.

[101] Isosävi, S., Diab, S., Kangaslampi, S., Qouta, S., Kankaanpää, S., Puura, K., \& Punzmäki, R. (2017). Maternal trauma affects prenatal mental health and infant stress regulation among Palestinian dyads. Infant Mental Health Journal, 38 (5), 617633. doi: 10.1002/imhj.21658.

[102] Alpak, G., Unal, A., Bulbul, F., Sagaltici, E., Bez, Y., Altindag, A., \& Savas, H. A. (2014). Post-traumatic stress disorder among Syrian refugees in Turkey: A cross-sectional study. International Journal of Psychiatry in Clinical Practice, 19, 45-50. doi: 10.3109/13651501.2014.961930.

[103] The Surprisingly Powerful Influence of Drawing on Memory. Myra A. Fernandes, Jeffrey D. Wammes, Melissa E. Meade. Current Directions in Psychological Science. Volume: 27 issue: 5 , page (s): 302-308.

[104] Shapiro, F. Clinician's Corner: EMDR Therapy. International Society for Traumatic Stress Studies. Stress Points. (2016). Retrieved from http://www.istss.org/educationresearch/traumatic-stresspoints/2016-april/clinician-s-corneremdr-therapy.aspx. 